\title{
ESPÉCIES DE CERRADO COM POTENCIAL PARA RECUPERAÇÃO DE ÁREAS DEGRADADAS POR MINERAÇÃO DE OURO, PARACATU-MG ${ }^{1}$
}

\author{
Andreza Viana Neri², Michellia Pereira Soares ${ }^{3}$, João Augusto Alves Meira Neto ${ }^{4}$ e Luiz Eduardo Dias ${ }^{4}$
}

\begin{abstract}
RESUMO - Com o intuito de selecionar espécies que possam ser testadas na recuperação de áreas com alta concentração de arsênio, foram estudadas 10 áreas de Cerrado degradadas pelo garimpo de ouro em Paracatu, MG. Utilizou-se a escala de valores de cobertura e abundância de Braun-Blanquet, sendo as espécies classificadas também quanto à forma de vida de Raunkiaer. As áreas foram comparadas floristicamente pelo índice de Sørensen. Foram encontradas 197 morfoespécies lenhosas e herbáceas, das quais 102 foram identificadas em nível específico, 35 em gênero e 40 em família. Vinte morfoespécies não puderam ser identificadas. Houve grande variação quanto à riqueza florística entre as unidades amostrais (21-53 espécies), e esse fato influenciou a formação de três grupos na análise de similaridade florística. As espécies que se mostraram mais abundantes e provavelmente de maior adaptabilidade às condições ambientais foram: Axonopus marginatus, Simarouba amara, Aristida ekmaniana, Digitaria ciliaris, Stylosanthes viscosa, Andropogon bicornis, Maprounea guianensis e Sabicia brasiliensis. A forma de vida mais frequente foi fanerófito, seguida de hemicriptófito e caméfito. No espectro biológico, foi possível visualizar as diferentes estruturas das áreas estudadas, enfatizando-se a diversidade de ambientes presentes, apesar de apresentarem baixa riqueza florística.
\end{abstract}

Palavras-chave: Braun-Blanquet, Similaridade florística e Forma de vida e savana.

\section{CERRADO SPECIES WITH POTENTIAL FOR RECOVERY OF DEGRADED AREAS FOR GOLD MINING, PARACATU-MG}

\begin{abstract}
The objective of this work was to study species that can be tested in the recovery of Arsenio high concentration areas. Therefore, 10 cerrado areas degraded by gold exploration in Paracatu-MG, Brazil were studied. It was used the Braun-Blanquet cover value and abundance scale. The species were classified by the Raunkiaer life form. The areas were floristically compared by Sørensen index. Out of 197 woody and herbs morpho-species found, 102 were identified at specific level, 35 at genus level and 40 at family level. Twenty morpho-species could not be identified. There was a great floristic richness among sample units (21-53 species), which influenced the formation of three groups in floristic similarity analysis. The more abundant and probably more adapted species to the environmental conditions were Axonopus marginatus, Simarouba amara, Aristida ekmaniana, Digitaria ciliaris, Stylosanthes viscosa, Andropogon bicornis, Maprounea guianensis and Sabicia brasiliensis. The most frequent form of life was phanerophyte followed by hemicryptophyte and chamephyte. In the biological spectra, it was possible to visualize the different structure of the studied areas, emphasizing the environmental diversity present despite presenting low floristic richness.
\end{abstract}

Keywords:Braun Blanquet, Floristic similarity, Life form and Savannah.

\section{INTRODUÇÃO}

O Cerrado é um bioma que se apresenta segundo um gradiente de biomassa, que pode ser subdividido em campo limpo, campo sujo, campo cerrado, cerrado típico e cerradão. Essa divisão baseia-se apenas na fisionomia da vegetação, visto que a composição florística entre as várias fisionomias de cerrado varia significativamente (FERRI, 1977).

O Cerrado como um todo não é uma vegetação caracterizada por uma única flora, mas duas, sendo

\footnotetext{
${ }^{1}$ Recebido em 28.05.2008 e aceito para publicação em 20.04.2011.

${ }^{2}$ Departamento de Biologia Vegetal, Universidade Federal de Viçosa, UFV, Brasil. E-mail: <andreza.neri@ufv.br>.

${ }^{3}$ Instituto Federal Goiano - Campus Rio Verde, IFGOIANO, Brasil. E-mail: <michelliabot@hotmail.com>.

${ }^{4}$ Departamento de Solos, Universidade Federal de Viçosa, UFV, Brasil. E-mail: <j.meira@ufv.br>.
} 
uma herbáceo-subarbustiva e outra lenhosa. Ambas se distribuem por toda a extensão do Cerrado, mas não de forma homogênea. Apenas o campo limpo e o cerradão possuem caracteres mais marcantes, o primeiro por ser uma vegetação campestre e a outra, uma vegetação florestal (COUTINHO, 1978). Diante das diferenças florísticas e fitofisionômicas, esse autor conceituou as formas savânicas de Cerrado (campo sujo, campo cerrado e cerrado stricto sensu) como formas ecotonais entre o campo limpo e o cerradão. Esse bioma pode ser caracterizado também por apresentar vegetação com sinúsias de hemicriptófitas, geófitas e fanerófitas oligotróficos de pequeno porte, com ocorrência em toda a Zona Neotropical (VELOSO, 1992).

O crescimento econômico brasileiro e a criação de Brasília geraram forte pressão sob extensas áreas de Cerrado em Minas Gerais, sendo este último fator importante que implicou a criação de estrutura viária em regiões ocupadas por Cerrado, principalmente a Rodovia Rio-Brasília, BR- 040 (MEIRA NETO, 2003). Nas duas últimas décadas, a região do Cerrado tem sido opção preferencial para a expansão da fronteira agrícola. Além dessa atividade, há nessa região aumento na demanda dos setores industriais e minerais (PINTO; BARROS, 1996).

Talvez em função da exploração que vem sofrendo há séculos não só da mineração, mas também da agricultura, Paracatu apresenta área com estados avançados de degradação. Trabalhos realizados por Felfili et al. (1993) demonstraram que as áreas de Cerrado em Paracatu apresentam baixa densidade, baixo valor de área basal e baixo índice de diversidade, comparado com outras áreas da Chapada Pratinha (GO/MG/DF).

Em regiões de atividade de exploração mineral, as áreas degradadas geralmente perdem sua estrutura e função, sendo necessário recuperar ou reabilitar o sítio degradado (PRIMACK; MASSARDO, 2001). Nesses casos, a combinação da preparação do sítio, o manejo do hábitat e a introdução de espécies nativas permitem que gradualmente o ecossistema ganhe espécies e características do sítio original (PRIMACK; MASSARDO, 2001).

Escolher corretamente a comunidade de plantas que irá iniciar o processo de sucessão em uma área degradada é um dos pontos mais críticos do processo de recuperação. Estudos fitossociológicos de ambientes naturais preservados, alterados, perturbados e degradados têm como objetivo não apenas a escolha das espécies, mas, também, descobrir como empregá-las eficientemente nos projetos de recuperação. A tentativa de reprodução das estruturas das comunidades vegetais parece ser o melhor caminho, pois tem sido largamente empregada com bons resultados (CORRÊA; MELO FILHO, 1998).

Com o intuito de conhecer e selecionar espécies que tenham potencial para serem usadas na recuperação de áreas degradadas na Rio Paracatu Mineração (RPM) e auxiliar no manejo adequado dessas espécies, estudaram-se 10 áreas de Cerrado em regeneração sobre substrato filitoso contendo sulfetos metálicos na Rio Paracatu Mineração.

\section{MATERIAL E MÉTODOS}

\subsection{Caracterização da área}

O Município de Paracatu fica localizado no Noroeste de Minas Gerais, a 480 km da capital Belo Horizonte e a $230 \mathrm{~km}$ do Distrito Federal. O estudo foi realizado dentro da Rio Paracatu Mineração (RPM), empresa cuja atividade compreende mineração a céu aberto no Morro do Ouro.

O levantamento foi realizado em sete áreas (10 unidades amostrais) de Cerrado em regeneração natural após anos de garimpo. Este, em Paracatu, teve início no século XVIII (CARVALHO, 1992), e não há registro do término dessa atividade na área de estudo. Segundo funcionários da RPM, essas não são garimpadas desde o início do século XX. As áreas estudadas estão em regiões ainda não mineradas pela empresa.

As áreas selecionadas para estudo representam ambientes distintos, em diferentes estágios sucessionais. O local amostrado no Tanque C apresenta vegetação fisionomicamente semelhante à do cerrado s.s., assim como a Reserva do Mundéu, onde uma das parcelas representa a fitofisionomia mais aberta de cerrado (campo cerrado) e a outra a mais fechada (cerrado s. s.). A Reserva do Mundéu é a área em estágio mais avançado de regeneração e, provavelmente, a que está em pousio há mais tempo. Em contraposição, São Domingos é o ambiente com grau de degradação mais recente. Nessa área, uma parcela foi instalada sobre vegetação campestre com grande umidade e sujeita a encharcamento e, a outra, sobre uma região mais seca, com boa drenagem, mas com solo pouco coberto, onde predomina a gramínea Urochloa sp. 
Os ambientes estudados na Grota de Macacos, Grota de Vênus, Tanque 1 e Córrego Rico apresentam níveis de degradação semelhantes, na qual a vegetação cresce sobre substrato rochoso (filito).

\subsection{Amostragem}

A amostragem foi realizada em setembro de 2003. Para o levantamento das espécies foram selecionadas sete áreas pertencentes à RPM. Os ambientes estudados compreendem áreas de antigo garimpo que receberam as seguintes denominações: Grota de Macacos face Leste (MFL), Grota de Macacos face Oeste (MFO), Tanque C(TC), Tanque 1(T1) São Domingos 1(SD1), São Domingos 2 (SD2), Córrego Rico (CR), Reserva do Mundéu 1 (RM1), Reserva do Mundéu 2 (RM2) e Grota de Vênus (VE). Em cada área foi estabelecida uma parcela amostral de 10 m x 10 m, com exceção da Reserva do Mundéu, Grota de Macacos e São Domingos, onde foram estabelecidas duas parcelas. Todos os indivíduos presentes nas unidades amostrais foram inventariados, já que se tinha interesse tanto no estrato herbáceo-subarbustivo quanto no estrato arbustivo-arbóreo.

Para a análise de estrutura foi utilizada a escala de valor de cobertura e abundância de Braun-Blanquet (1965 citada por MUELLER-DOMBOIS; ELLENBERG, 1974). Essa é uma metodologia referida na literatura como análise semiquantitativa, em função de seu largo intervalo na escala de valores. Pode ser usada em estudos das mais diversas comunidades vegetais, em que a escala de valores é a combinação de dois parâmetros: a cobertura, que é representada pelos quatro primeiros valores da tabela; e a abundância pelas três últimas escalas de valores (MUELLER-DOMBOIS; ELLENBERG, 1974).

A identificação do material botânico foi realizada em nível de família, gênero e espécie, com o auxílio de literatura especializada, consulta a especialistas e consulta ao Herbário VIC da Universidade Federal de Viçosa. Para classificação dos táxons foi utilizado o sistema de Cronquist (1981), exceto para Leguminosae, em que foi considerado APG II (SOUZA; LORENZI, 2005), e para confirmação da grafia das espécies e nome dos respectivos autores foram utilizadas as informações disponíveis no site do Mobot (www.mobot.org).

Para espécies amostradas e identificadas em nível específico, determinou-se a forma de vida de acordo com a classificação de Raunkiaer (1934 citado por MUELLER-DOMBOIS; ELLENBERG 1974) para posterior confecção do espectro biológico.
O sistema de classificação de Raunkiaer é orientado ecologicamente e baseado na posição das gemas apicais ou órgãos dos quais novos ramos ou folhas se desenvolvem após a estação desfavorável. A composição dessas formas de vida em adição à composição de espécies é de especial interesse por fornecer informações a respeito da resposta da comunidade aos fatores ambientais e também o estádio de sucessão. A classificação quanto à forma de vida de Raunkiaer tem sido citada em trabalhos no Brasil, principalmente em áreas de Cerrado (MANTOVANI; MARTINS, 1993; BATALHA et al., 1997; BATALHA; MANTOVANI, 2001; BATALHA; MARTINS, 2002ab; BATALHA; MARTINS, 2004), em que os autores destacaram a variação dos componentes da vegetação ao longo das fitofisionomias. Em outras formações vegetais, podem-se citar, principalmente, trabalhos relacionados com campos de altitude ou inselbergs (MEIRELLES et al., 1999; CAIAFA; SILVA, 2005).

A partir da classificação das espécies, os resultados puderam ser expressos em um espectro biológico florístico, que é dado pela representação gráfica da porcentagem do número de espécies pertencentes a cada forma de vida de diferentes regiões e de diferentes tipos de vegetações (CAIN, 1950). Para a análise das formas de vida, utilizou-se a chave dos principais grupos de formas de vida de Raunkiaer, conforme MuellerDombois e Ellenberg (1974).

A partir de uma matriz de presença e ausência de espécies, foi avaliada a similaridade florística entre as áreas estudadas utilizando o índice de similaridade de Sørensen (BROWER; ZAR, 1984).

A similaridade florística entre as áreas foi verificada pelo método de médias não ponderadas (UPGMA) (SNEATH; SOKAL, 1973). Os resultados foram expressos na forma de dendrograma obtido através do programa Fitopac 1 (SHEPHERD, 1996).

\section{RESULTADOS E DISCUSSÃO}

\subsection{Valores de cobertura e abundância}

Nas unidades amostrais estudadas na RPM foram encontradas 197 morfoespécies lenhosas e herbáceas, 192 pertencentes à divisão Magnoliophyta e cinco à divisão Pteridophyta. Dessas 102 foram identificadas no nível específico, 35 no nível de gênero e 40 no nível de família. Vinte das morfoespécies não puderam ser identificadas. As famílias que apresentaram maior riqueza

Revista Árvore, Viçosa-MG, v.35, n.4, p.907-918, 2011 
eram representantes tanto da flora herbácea quanto da flora lenhosa. São elas: Leguminosae (25 spp.), Poaceae (20 spp.), Asteraceae (13 spp.), Malpighaceae (11 spp.), Myrtaceae (11 spp.), Cyperaceae (10 spp.), Melastomataceae (10 spp.) e Rubiaceae (9 spp.).

Houve grande variação com relação à riqueza florística entre as unidades amostrais (53 - 21 espécies), e isso pode ter ocorrido em função das variações ambientais apresentadas pelas diferentes áreas, algumas sujeitas a encharcamento e outras apresentando substrato bastante oxidado com visível estresse hídrico, e também pode ter sido em função do tempo que as áreas estão em regeneração. As áreas que apresentaram os maiores números de espécies foram RM1 e CR, ambas com 53 espécies, RM2 (45 espécies) e SD1 (43 espécies). Já as áreas estudadas em SD2 (22 espécies), T1 (22 espécies) e MFO (21 espécies) foram as que apresentaram menor riqueza florística.

A parcela encharcada em SD1 apresentou grande número de espécies exclusivas, porém estas tiveram baixo valor de cobertura e abundância. Nessa unidade amostral, as espécies que se destacaram quanto ao parâmetro anterior foram Urochloa sp., Stylosanthes viscosa e Andropogon bicornis. Em função das características do ambiente, como a presença de alta umidade, essas espécies se mostram potencias para regeneração inicial da bacia de rejeito da RPM, com exceção de Urochloa sp.

A parcela amostrada no T1 apresentou o segundo menor número de espécies, possivelmente em função de estarem estabelecidas sobre rejeito, que apresentam características químicas e físicas adversas às demais espécies. Aqui se destacaram espécies importantes quanto ao valor de cobertura, as quais também foram observadas em outros locais. São elas: Axonopus marginatus, Axonopus pressus, Aristida ekmaniana e Simarouba amara.

As espécies Axonopus marginatus, Vochysia thyrsoidea, Curatela americana, Echinolaena inflexa, Byrsonima verbascifolia e Erythroxylum tortuosum são espécies que apresentaram os maiores valores de cobertura na RM1. Já em RM2 se destacaram as espécies Fuirena umbellata, Byrsonima coccolobifolia, Erythroxylum daphnites e Aspidosperma macrocarpum. Apesar da pouca distância entre essas duas áreas, elas não apresentaram a semelhança florística esperada. Isso enfatiza não só uma variação estrutural observada pelas diferenças com relação à abundância das espécies que ocorreram em ambas as áreas, mas, também, uma variação florística dentro da reserva. Essas diferenças podem estar relacionadas tanto com fatores edáficos quanto com a topografia, visto que a parcela RM1 foi alocada em uma porção mais alta da encosta que a parcela RM2.

Na análise de cobertura foi possível observar que as espécies arbóreas: Simarouba amara e Maprounea guianensis e as espécies herbáceas: Axonopus marginatus, Aristida ekmaniana, Digitaria ciliaris, Stylosanthes viscosa, Andropogon bicornis e Sabicia brasiliensis foram aquelas que ocorreram em $60 \%$ ou mais das unidades amostrais. Essas espécies foram as mais frequentes e, provavelmente, possuem maior adaptabilidade às condições existentes na RPM. Como se trata de ambiente onde a luminosidade não é fator limitante para o estabelecimento das plantas, também não é possível inferir sobre o seu grupo ecológico.

Essas espécies podem representar um grupo de grande importância em processos de recuperação, principalmente por representarem diferentes estratos: herbáceo e lenhoso. Nesse grupo, as gramíneas apresentaram-se em maior número, destacando as espécies Axonopus marginatus, Aristida ekmaniana, Digitaria ciliaris e Andropogon bicornis.

A espécie Aristida ekmaniana esteve presente em 70\% das áreas amostradas com cobertura razoável, ao contrário do que ocorreu no TC, onde essa espécie apresentou grande cobertura. Essa unidade amostral foi a que mostrou vegetação mais fechada. Porém, observou-se que a ocorrência da espécie Aristida ekmaniana não se limitou a esse tipo de ambiente, já que também foi encontrada em áreas abertas com grande abundância, como dentro da cava da mina. Aristida ekmaniana apresenta ocorrência principalmente em áreas de Cerrado ou áreas adjacentes (WANDERLEY et al., 2001), sendo assim uma espécie importante no estrato herbáceo desse bioma.

As espécies lenhosas que se destacaram neste estudo foram: Simarouba amara, Maprounea guianensis, Stylosanthes viscosa e Sabicia brasiliensis. Dessas, apenas as duas primeiras compõem o estrato arbóreo, enquanto as duas seguintes, apesar de serem lenhosas, são de pequeno porte e compõem o que no Cerrado é denominado estrato herbáceo-subarbustivo. 
Entre as famílias que compõem a flora do Cerrado, destaca-se a Leguminosae, tanto pela representatividade quanto pela sua importância dentro da fixação simbiótica de nitrogênio (CORDEIRO, 2002). Das leguminosas de Cerrado encontradas na RPM, Stylosanthes viscosa é uma espécie que apresenta nodulação em todo o sistema radicular, como foi constatado por Cordeiro (1986 citado por CORDEIRO, 2002), merecendo, assim, atenção particular e podendo ser testada juntamente com as espécies iniciais da sucessão.

Uma observação de campo bastante relevante é o fato de a espécie Simarouba amara ter apresentado indivíduos vigorosos e grande abundância na Grota dos Macacos. Porém, essa espécie possui pouca resistência ao fogo. No T1, onde ocorreu queimada em 2002, foram observados vários indivíduos jovens dessa espécie mortos pelo fogo.

Cabe destacar também outras espécies que, apesar de não terem sido tão frequentes, apresentaram valor de cobertura relevante nas áreas onde ocorreram. São elas: Urochloa sp., Axonopus pressus, Curatela americana, Marcetia taxifolia, Ouratea castaneifolia, Fuirena umbellata e Hirtella hebeclada.

A Urochloa sp. foi amostrada apenas em São Domingos, onde sua ocorrência pode ter-se dado por ação antrópica. Apesar de ser espécie exótica e pouco recomendada na recuperação de áreas degradadas, em São Domingos ela apresentou excelente cobertura, tanto na área úmida quanto na área seca. Tal espécie é extremamente agressiva, competindo com as nativas do Cerrado, principalmente com as do estrato herbáceo. Por isso, tem que se ter muito cuidado no manejo dessa espécie. Seu predomínio em relação a espécies nativas pode vir a prejudicar a comunidade vegetal, bem como a fauna associada àquele ecossistema (dispersão, polinização...). Já Axonopus pressus mostrou maior sucesso na área $\mathrm{T} 1$, onde as condições ambientais, talvez, tenham sido limitantes para muitas outras espécies.

Curatela americana e Ouratea castaneifolia apresentaram alta cobertura em poucas áreas e foram encontradas em áreas menos perturbadas (RM1, CR, RM2 e TC). Como são espécies lenhosas, não é possível inferir se elas estão adaptadas às condições ambientais encontradas nessas áreas ou se estão no local desde o início da sucessão. Porém, a importância dessas espécies não pode ser descartada, já que se trata de espécies frequentes em levantamento de Cerrado (OLIVEIRA FILHO; MARTINS, 1991; FELFILI et al., 1993; ARAÚJO et al., 1997; MUNHOZ; PROENÇA, 1998; BATALHA; MANTOVANI, 2001; COSTA; ARAÚJO, 2001), principalmente Curatela americana (RATTER et al., 2003). As outras três espécies, Fuirena umbellata, Marcetia taxifolia e Hirtella hebeclada, parecem suportar condições ambientais mais críticas, alta umidade e pobreza de solo.

No processo de recuperação de áreas degradadas merecem destaque as espécies herbáceas: Axonopus pressus, Axonopus marginatus, Aristida ekmaniana, Digitaria ciliaris e Andropogon bicornis, representando o início de sucessão, sendo todas elas da família Poaceae. Outras que também se mostraram importantes para início de sucessão foram: Stylosanthes viscosa, Sabicia brasiliensis, Marcetia taxifolia e Fuirena umbellata. Das espécies lenhosas (arbustivo-arbóreas), destacam-se: Simarouba amara, Hirtella hebeclada, Maprounea guianensis, Curatela americana e Ouratea castaneifolia.

Além das espécies encontradas nas unidades amostrais, foram registradas outras que tiveram ocorrência nas proximidades, como: Tabebuia ochracea, Cecropia sp., Hirtella selloana, Machaerium opacum, Solanum lycocarpum, Hymenaea stigonocarpa, Plathymenia reticulata, Guapira noxia, Himatanthus obovatus, Salvertia convallariodora, Caryocar brasiliense, Dalbergia miscolobium, Senna obtusifolia e Qualea cordata.

\subsection{Formas de vida de Raunkiaer}

A distribuição das formas de vida segundo Raunkiaer (1934) encontra-se na Figura 1 e na Tabela 1, onde se destaca maior número de espécies fanerófitas, na maioria das áreas estudadas. As formas de vida hemicriptófitas e caméfitas também representaram boa parte das espécies amostradas, sendo as mais importantes em algumas áreas. Numa dessas áreas (SD1), o fator umidade parece ter sido responsável pelo menor número de espécies fanerófitas, o mesmo ocorrendo em outras áreas (SD2 e T1) em razão, possivelmente, da baixa disponibilidade de nutrientes em função da degradação pela garimpagem.

Revista Árvore, Viçosa-MG, v.35, n.4, p.907-918, 2011 
Reserva do Mundéu

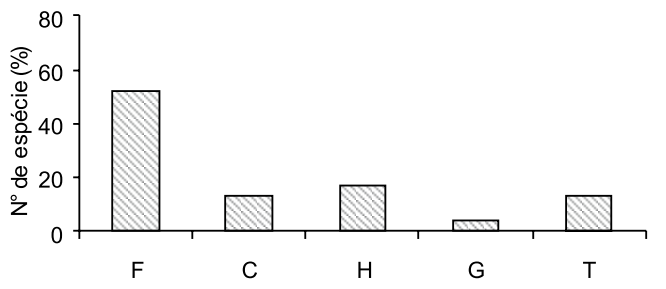

Reserva do Mundéu 2

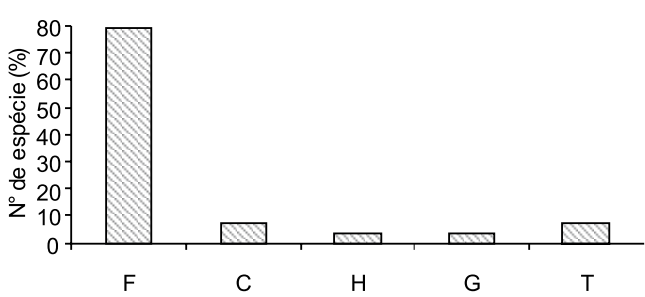

Tanque C

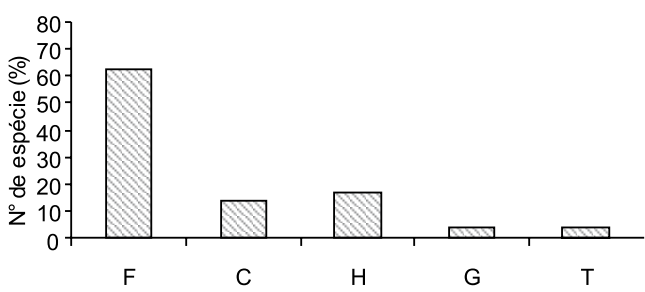

Grota de Macacos Face Leste

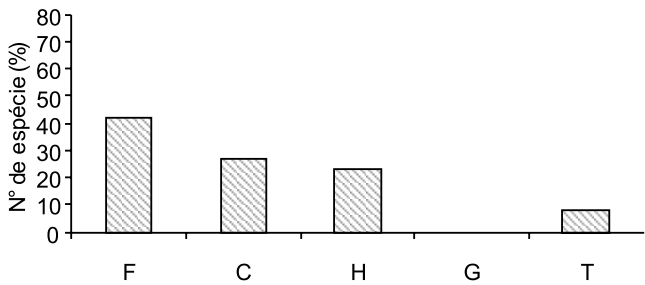

Grota de Macacos Face Oeste

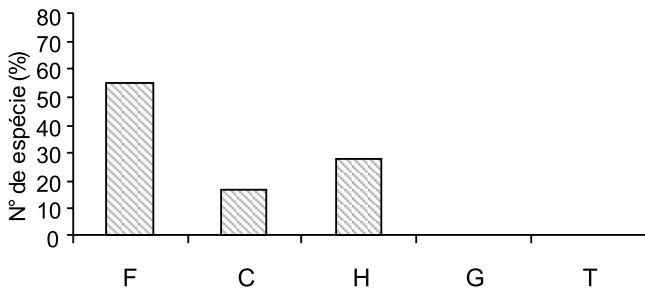

Córrego Rico
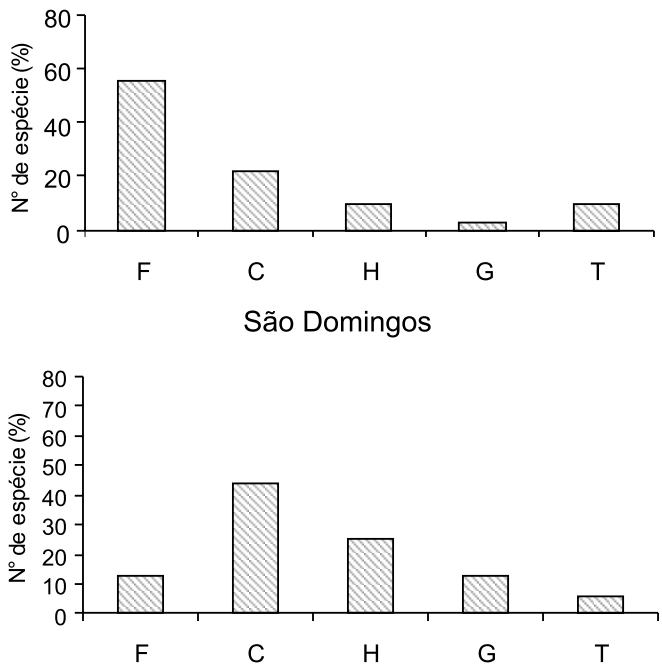

São Domingos 2

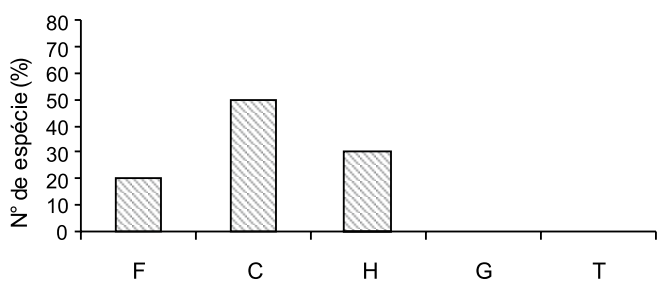

Grota de Vênus

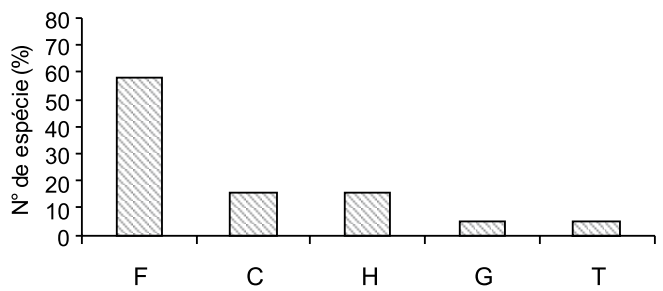

Tanque 1

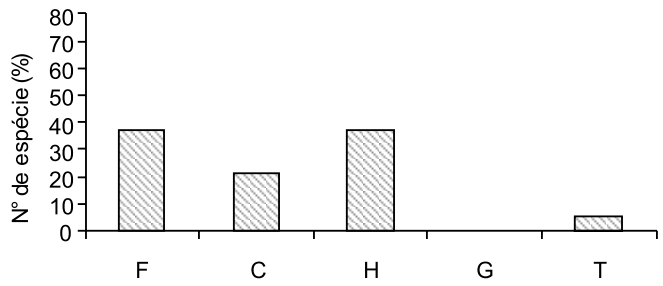

Figura 1 - Espectro biológico das espécies amostradas em diferentes áreas da Rio Paracatu Mineração (RPM), Paracatu, MG. Sendo: F- Fanerófitas, H- Hemicriptófitas, C-Caméfitas, T- Terófitas e G- Geófitas.

Figure 1 - Biological spectrum of species sampled in different areas of Rio Paracatu Mineração(RPM), Paracatu, MG. F-Phanerophytes, H-Hemicryptophytes, C-Chamaephytes, T-Therophytes and G-Geophytes.

Revista Árvore, Viçosa-MG, v.35, n.4, p.907-918, 2011 
Tabela 1 - Classificação quanto à forma de vida de Raunkiaer (1934 citado por MUELLER-DOMBOIS; ELLENBERG, 1974) de algumas espécies amostradas em diferentes áreas pertencentes à Rio Paracatu Mineração, Paracatu (RPM), MG.

Table 1 - Raunkiaer life form (1934 apoud Mueller-Dombois \& Ellenberg 1974) classification of some species sampled in different areas in Rio Paracatu Mineração (RPM), Paracatu, MG.

\begin{tabular}{|c|c|c|}
\hline Família & Espécie & Forma de vida \\
\hline Anacardiaceae & $\begin{array}{l}\text { Myracronduon urundeuva Allem. } \\
\text { Tapirira guianensis Aubl. }\end{array}$ & $\begin{array}{l}\text { Fanerófita } \\
\text { Fanerófita }\end{array}$ \\
\hline Annonaceae & $\begin{array}{l}\text { Annona coriacea Mart. } \\
\text { Xylopia aromatica Mart. }\end{array}$ & $\begin{array}{l}\text { Fanerófita } \\
\text { Fanerófita }\end{array}$ \\
\hline Apocynaceae & $\begin{array}{l}\text { Aspidosperma macrocarpon Mart. } \\
\text { Hancornia speciosa Gomes }\end{array}$ & $\begin{array}{l}\text { Fanerofita } \\
\text { Fanerófita }\end{array}$ \\
\hline Araliaceae & Didymopanax macrocarpa Seem. & Fanerófita \\
\hline \multirow[t]{8}{*}{ Asteraceae } & Acanthospermum australe (Loefl.) Kuntze & Caméfitoa \\
\hline & $\begin{array}{l}\text { Eremanthus erythropappus (DC.) MacLeish } \\
\text { Eupatorium oxylepis DC. }\end{array}$ & Fanerófita \\
\hline & Eupatorium squalidum DC. & Terófita \\
\hline & Piptocarpha rotundifolia (Less.) Baker & Fanerófita \\
\hline & Trichogonia melissaefolia (DC.) Mattf. in Pilger & \\
\hline & Vernonia aurea Mart. ex DC. & Caméfita \\
\hline & Vernonia brasiliana (L.) Druce & Fanerófita \\
\hline & Vernonia desertorum Mart. ex. DC. & \\
\hline Bignoniaceae & Anemopaegma arvense (Vell.) Stellfeld \& J.F. Souza & Geófita \\
\hline Chrysobalanaceae & Hirtella hebeclada Moric. ex DC.. & Fanerófita \\
\hline Clusiaceae & Kielmeyera coriacea Mart. \& Zucc.. & Fanerófita \\
\hline Convolvulaceae & Merremia tomentosa (Choisy) Hallier & Caméfita \\
\hline \multirow[t]{6}{*}{ Cyperaceae } & Bulbostylis capillaris (L.) C.B. Clarke & Hemicriptófita \\
\hline & Cyperus lanceolatus Poir. & Geófita \\
\hline & Cyperus luzulae (L.) Rottb. ex Retz. & Geófita \\
\hline & Eleocharis cf. geniculata (L.) Roem. \& Schult. & Terófita \\
\hline & Fimbristylis cf. autumnalis (L.) Roem. \& Schult. & Terófita \\
\hline & $\begin{array}{l}\text { Fulrena umbellata Rottb. } \\
\text { Rhynchospora nervosa (Vahl) Boeck. }\end{array}$ & Geófita \\
\hline Dennstaedtiaceae & Lindsaea stricta (Sw.) Dryand. & Hemicriptófita \\
\hline Dilleniaceae & Curatella americana L. & Fanerófita \\
\hline \multirow[t]{3}{*}{ Erythroxylaceae } & Erythroxylum daphnites Mart. & Fanerófita \\
\hline & Erythroxylum suberosum A. St. - Hil. & Fanerófita \\
\hline & Erythroxylum tortuosum Mart. & Fanerófita \\
\hline \multirow[t]{2}{*}{ Euphorbiaceae } & Maprounea guianensis Aubl. & Fanerófita \\
\hline & Pera glabrata Poepp. ex Baill. & Fanerófita \\
\hline Flacourtiaceae & Casearia sylvestris Sw. & Fanerófita \\
\hline Iridaceae & Trimezia juncifolia Klatt. & \\
\hline Lamiaceae & Hyptis reticulata Mart. ex Benth. & Caméfita \\
\hline \multirow[t]{13}{*}{ Leguminosae } & Bauhinia cf dumosa Benth. & Fanerófita \\
\hline & Bowdichia virgilioides Kunth. & Fanerófita \\
\hline & Chamaecrista cathartica (Mart.) H.S.Irwin \& Barneby & \\
\hline & Chamaecrista flexuosa (L.) Greene & Caméfita \\
\hline & Chamaecrista glandulosa (L.) Greene & \\
\hline & Chamaecrista nictitans subsp. Patelaria ( DC. ex Colladon ) & \\
\hline & H.S.Irwin \& Barneby & Caméfita \\
\hline & Desmodium barbatum (L.) Benth. & Caméfita \\
\hline & Desmodium incanum DC. & Caméfita \\
\hline & Hymenaea stigonocarpa Mart. ex Hayne & Fanerófita \\
\hline & Sclerolobium paniculatum Vog. & Fanerófita \\
\hline & Stylosanthes viscosa (L.) Sw. & Caméfita \\
\hline & Vatairea macrocarpa (Benth.) Ducke & Fanerófita \\
\hline
\end{tabular}


Tabela 1 - Cont.

Table 1 - Cont.

\begin{tabular}{|c|c|c|}
\hline Loganiaceae & Antonia ovata Pohl & Fanerofita \\
\hline \multirow[t]{3}{*}{ Lythraceae } & Cuphea linarioides Cham. \& Schltdl & Caméfita \\
\hline & Cuphea polymorpha A. St.-Hil. & Caméfita \\
\hline & Lafoensia pacari A. St.-Hil.. & Fanerófita \\
\hline \multirow[t]{7}{*}{ Malpighiaceae } & Banisteriopsis campestris (A. Juss.) Little & Fanerófita \\
\hline & Banisteriopsis cf anisandra (A. Juss) B. Gates & Fanerófita \\
\hline & Banisteriopsis malifolia (Ness \& Mart.) B. Gates & Fanerófita \\
\hline & Banisteriopsis stellaris (Grisebach) B. Gates & Fanerófita \\
\hline & Byrsonima cf crassa Nied. & Fanerófita \\
\hline & Byrsonima verbascifolia (L.) DC.. & Fanerófita \\
\hline & Byrsonima coccolobaefolia Kunth. & Fanerófita \\
\hline Malvaceae & Sida urens L. & Caméfita \\
\hline \multirow[t]{4}{*}{ Melastomataceae } & Marcetia taxifolia (A. St.-Hil.) DC. & Caméfita \\
\hline & Miconia albicans (Sw.) Triana & Fanerófita \\
\hline & Tibouchina granulosa (Desr.) Cogn. & Fanerófita \\
\hline & Trembleya parviflora (Don) Cogn. & Fanerófita \\
\hline \multirow[t]{7}{*}{ Myrtaceae } & Cambessedesia hilariana (Kunth) DC.. & Caméfita \\
\hline & Campomanesia eugenioides (Cambess.) D. Legrand & Fanerófita \\
\hline & Myrcia formosiana DC. & Fanerófita \\
\hline & Myrcia lingua (O. Berg) Mattos \& D. Legrand & Fanerófita \\
\hline & Myrcia sellowiana O. Berg & Fanerófita \\
\hline & Myrcia tomentosa (Aubl.) DC.. & Fanerófita \\
\hline & Psidium guajava $\mathrm{L}$. & Fanerófita \\
\hline Nyctaginaceae & Neea theifera Orste. & Fanerófita \\
\hline Ochnaceae & Ouratea castaneaefolia Engl. & Fanerófita \\
\hline Oxalidaceae & Oxalis densifolia Mart. ex Zucc.. & Geófita \\
\hline Poaceae & Andropogon bicornis L. & Hemicriptófia \\
\hline \multirow[t]{12}{*}{ Axonopus capillaris } & $\begin{array}{l}\text { Aristida ekmaniana Henrard } \\
\text { (Lam.) Chase }\end{array}$ & $\begin{array}{l}\text { Hemicriptófita } \\
\text { Terófita }\end{array}$ \\
\hline & Axonopus marginatus (Trin.) Chase & Hemicriptófita \\
\hline & Axonopus pressus (Nees ex Steud.) Parodi & Hemicriptófita \\
\hline & Ctenium cirrosum (Nees) Kunth & Hemicriptófita \\
\hline & Digitaria ciliaris (Retz.) Pers. & Terófita \\
\hline & Echinolaena inflexa (Poir.) Chase & Terófita \\
\hline & Melinis minutiflora P. Beuav. & Hemicriptófita \\
\hline & Rhynchelytrum repens (Willd.) C.E. Hubb. & Hemicriptófita \\
\hline & Setaria parviflora (Poiret) Kerguélen & Hemicriptófita \\
\hline & Setaria vulpiseta (Lam.) Roem. \& Schult. & Hemicriptófita \\
\hline & Sporobolus cubensis Hitchcock & Hemicriptófita \\
\hline & Urochloa brizantha (Hochst. ex A. Rich.) Stapf & Hemicriptófita \\
\hline \multirow[t]{7}{*}{ Rubiaceae } & Alibertia edulis (Rich.) A. Rich. ex DC. & Fanerófita \\
\hline & Alibertia lanceolata Cham. & Fanerófita \\
\hline & Borreria capitata (Ruiz \& Pav.) DC. & Caméfita \\
\hline & Declieuxia fruticosa (Willd. ex Roem. \& Schult.) Kuntze & Caméfita \\
\hline & Diodia teres Walter & Terófita \\
\hline & Sabicea brasiliensis Wernham & Caméfita \\
\hline & Tocoyena formosa (Cham. \& Schltdl.) K. Schum. & Fanerófita \\
\hline Sapindaceae & Matayba elaeagnoides Radlk. & Fanerófita \\
\hline Simaroubaceae & Simarouba amara Aubl. & Fanerófita \\
\hline Styracaceae & Styrax camporum Pohl & Fanerófita \\
\hline \multirow[t]{2}{*}{ Vochysiaceae } & Qualea parviflora Mart. & Fanerófita \\
\hline & Vochysia thyrsoidea Pohl & Fanerófita \\
\hline
\end{tabular}

Revista Árvore, Viçosa-MG, v.35, n.4, p.907-918, 2011 
Batalha e Martins (2002a), estudando espécies encontradas por outros autores que avaliaram diferentes áreas do Cerrado brasileiro (WARMING, 1892; BATALHA et al., 1997; BATALHA; MANTOVANI, 2001; BATALHA; MARTINS, 2002b), relataram que nos cerrados há maior número de espécies fanerófitas e hemicriptófitas. O número de espécies fanerófitas tende a diminuir à medida que se depara com áreas mais abertas de Cerrado, como: campo cerrado, campo sujo ou campo limpo, visto que há diminuição de espécies lenhosas e aumento de herbáceas na sequência exposta (COUTINHO, 1978).

Com o espectro biológico, é possível visualizar as diferentes fitofisionomias, representando diferentes estágios sucessionais na área da RPM. Isso fica evidente ao comparar o histograma (Figura 1) das áreas de São Domingos com a dos demais histogramas. Estes mostram que as duas áreas de São Domingos representam uma vegetação mais campestre em função da menor percentagem de espécies fanerófitas. Nessas áreas, as espécies caméfitas foram as mais expressivas.

Considerando que as áreas amostradas estão em processo de sucessão, os ambientes que apresentaram estruturas mais avançadas foram as do CR, da RM2 e do TC. Seus histogramas evidenciaram a predominância de fanerófitas e menor ocorrência das outras formas de vida. Dessas áreas, apenas o TC apresentou espécies hemicriptófitas mais expressivas que as caméfitas. Além dessas unidades amostrais, as áreas da RM1, VE, MFL e MFO apresentaram grande percentagem de fanerófitas.

O histograma do T1 (Figura 1) mostra a predominância de fanerófitas juntamente com as hemicriptófitas. A presença marcante dessa forma de vida nesse local mostra a capacidade adaptativa dessas espécies em colonizar áreas com condições ambientais adversas, especialmente com presença de fogo e pastejo. Espécies de gramíneas são os principais representantes das hemicriptófitas. Estas demonstram ser espécies com grande potencial para processos de recuperação de áreas degradadas, principalmente na fase inicial.

O aumento percentual de espécies fanerófitas e a diminuição percentual de espécies de outras formas de vida indicam tendência ao desenvolvimento da vegetação aberta em direção a uma vegetação de cerrado mais fechado, como o cerrado stricto sensu.
Nas áreas mais abertas, as hemicriptófitas têm proporção maior de espécies, pois constituem uma forma de vida que se beneficia da ausência de cobertura de plantas maiores e parecem se beneficiar da passagem de fogo, como o ocorrido no Tanque 1, ao contrário da espécie fanerófita Simarouba amara, que se mostrou sensível.

As espécies hemicriptófitas parecem ter grande potencial para serem utilizadas no processo inicial de recuperação, já que aparecem com boa cobertura, principalmente nas áreas mais abertas. Entre as hemicriptófitas que foram amostradas na área, destacam-se as espécies da família Poaceae: Axonopus marginatus, Aristida ekmaniana, Andropogon bicornis e Axonopus pressus. Aristida ekmaniana é uma espécie que mostrou ter bom desenvolvimento tanto em áreas mais fechadas quanto em áreas mais abertas, podendo ser uma colonizadora definitiva dessas áreas. Digitaria ciliaris, apesar de ser uma terófito, também é uma espécie com grande potencial, visto que apresentou abundância considerável.

\subsection{Similaridade florística}

A similaridade florística entre as unidades amostrais variou bastante, apresentando tanto áreas com altos valores de similaridade quanto áreas que, apesar da pequena distância, mostraram-se pouco similares. A partir da análise de cluster foi possível verificar a formação de três grupos (Figura 2).

O primeiro grupo e o com maior ligação florística $(0,40)$ foi formado pelas áreas de MFL, T1, MFO e TC. Nesse grupo, MFL e T1 apresentaram a maior similaridade florística, provavelmente por apresentarem exposição do substrato filitoso de forma semelhante; nessas áreas, o filito está bastante exposto, sendo fator seletivo para muitas espécies. O segundo grupo, com similaridade um pouco menor $(0,31)$, foi formado por RM1, CR e RM2. Apesar de RM1 estar mais próxima de RM2, a primeira mostrou-se mais similar floristicamente à área do CR. Essa maior similaridade pode estar relacionada à posição das áreas nas encostas, já que ambas estão na porção superior, enquanto a RM2 está na base encosta. Cabe ressaltar que RM e CR estão em áreas distintas.

Já o terceiro grupo formado pelas duas áreas amostradas em São Domingos apresentou baixa similaridade $(0,24)$. Um possível fator seletivo nessa

Revista Árvore, Viçosa-MG, v.35, n.4, p.907-918, 2011 


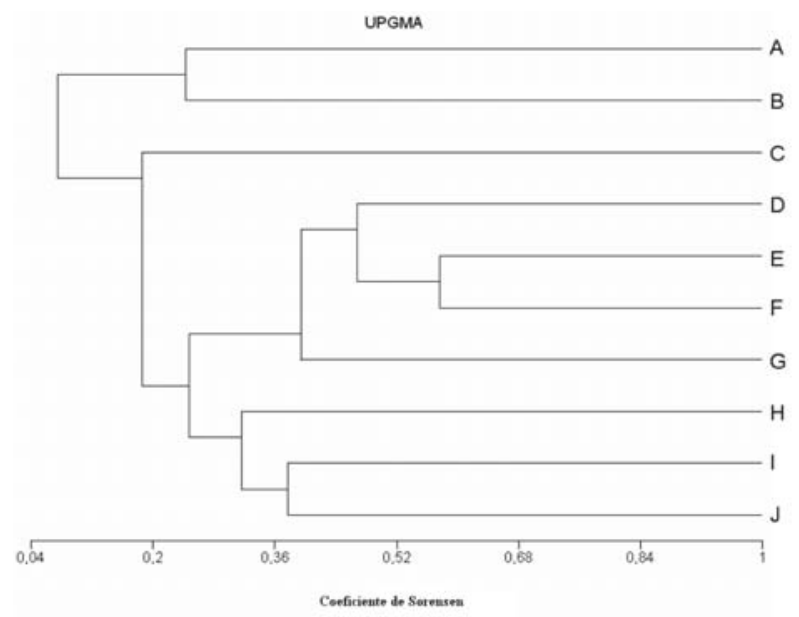

Figura 2 - Dendrograma de similaridade florística baseado no índice de Sørensen para as espécies amostradas na Rio Paracatu Mineração, Paracatu, MG. ASão Domingos 2, B- São Domingos 1, C- Grota de Vênus; D- Grota de Macacos Face Oeste; ETanque 1; F- Grota de Macacos Face Leste; GTanque C; H- Reserva do Mundéu 2; I- Córrego Rico; e J- Reserva do Mundéu 1.

Figure 2 - Floristic similarity dendogram based on Sørensen index for species sampled in Rio Paracatu Mineração, Paracatu-MG. A-São Domingos 2, B-São Domingos, $\boldsymbol{C}$-Grota de Vênus; $\boldsymbol{D}$ - Grota de Macacos Face Oeste; E-Tanque 1; F- Grota de Macacos Face Leste; $\boldsymbol{G}$ - Tanque C; $\boldsymbol{H}$-Reserva do Mundéu 2; I-Córrego Rico; and J-Reserva do Mundéu.

área responsável pela baixa similaridade entre as unidades amostrais foi a água, já que SD1 é uma área sujeita a encharcamento frequente, ao contrário de SD2, que possui melhor drenagem.

Das unidades amostrais estudadas, a da VE foi a que se mostrou menos similar floristicamente.

Com a comparação florística foi possível visualizar também diversidade de ambientes em função da formação dos diferentes grupos, apesar da baixa riqueza das áreas estudadas.

\section{CONCLUSÕES}

O espectro biológico mostrou que há maior percentual de espécies hemicriptófitas nas áreas em estágio inicial de sucessão que nas áreas em estágios mais avançados, mostrando a importância dessas formas de vida na fase inicial dos projetos de recuperação de áreas degradadas.

Revista Árvore, Viçosa-MG, v.35, n.4, p.907-918, 2011
De acordo com os resultados, as espécies hemicriptófitas: Axonopus marginatus, Axonopus pressus, Digitaria ciliaris, Aristida ekmaniana e Andropogon bicornis podem ser utilizadas na fase inicial de projetos de recuperação de áreas degradadas.

Em associação com as espécies hemicriptófitas, recomenda-se o uso de espécies de outras formas de vida, que na Rio Paracatu Mineração mostraram-se melhor adaptadas. Entre estas, destacam-se as fanerófitas: Simarouba amara, Maprounea guianensis, Curatela americana, Ouratea castaneifolia e Hirtella hebeclada; e as caméfitas: Stylosanthes viscosa, Sabicia brasiliensis e Marcetia taxifolia também apresentaram boa cobertura na área. Entre as caméfitas, Stylosanthes viscosa é a que merece maior atenção pela nodulação das raízes. Apesar do pequeno porte, ela é uma espécie que consegue cobrir extensas áreas, além de contribuir para o melhoramento do solo.

A Urochloa sp., por ser espécie exótica e com agressiva capacidade de dispersão e colonização, não deve ser usada em programas de revegetação, já que representa forte competidora, em detrimento das espécies nativas.

Será necessário testar as espécies sob os substratos para avaliar a germinação e o estabelecimento delas para uma seleção mais refinada, já que áreas degradadas por mineração apresentam condições ambientais críticas.

\section{AGRADECIMENTOS}

À RPM, pelo apoio durante a pesquisa; e aos pesquisadores Fernando Alves Ferreira, Lorrayne de Barros Bosquetti, Rodney H. O. Viana e Gilmar Edilberto Valente, pelo auxílio na identificação de alguns taxa; à Dr. Alexandra Penedo de Pinho, pelo auxílio no trabalho de campo; e aos pareceristas anônimos, que contribuíram para o enriquecimento do texto.

\section{REFERÊNCIAS}

ARAÚJO, G. M. et al. Estrutura comunitária de vinte áreas de cerrados residuais no município de Uberlândia, MG. Daphne, v.7, n.2, p.7-14, 1997.

BATALHA, M. A.; ARAGAKI, S.; MANTOVANI, W. Variações fenológicas das espécies do cerrado em Emas (Pirassununga, SP). Acta Botanica Brasílica, v.11, n.1, p.61-78, 1997. 
BATALHA, M. A.; MANTOVANI, W. Floristic composition of the cerrado in the Pé-de-Gigante reserve (Santa Rita do Passa Quatro, Southeastern Brazil). Acta Botanica Brasílica, v.15, n.3, p.289-304, 2001.

BATALHA, M. A.; MARTINS, F. R. Biological spectra of cerrado sites. Flora, v.197, n.6, p.452-460, 2002 a.

BATALHA, M. A.; MARTINS, F. R. The vascular flora of the cerrado in Emas National Park (Goiás, Central Brazil). Sida, v.20, p.295-312, 2002 ${ }^{\text {b }}$

BATALHA, M. A.; MARTINS, F. R. Floristic, frequency, and vegetation life-form spectra of a cerrado site. Brazilian Journal Biology, v.64, n.2, p.203-209, 2004.

BROWER, J. E. \& ZAR, J. H. Field and laboratory methods for general ecology. Iowa, Wm. C. Brown Company, 1984. 226p.

CAIAFA, A. N. \& SILVA, A. F. Composição florística e espectro biológico de um Campo de Altitude na Serra do Estadual do Brigadeiro, Minas Gerais-Brasil. Rodriguésia, v.56, n.87, p.163-173, 2005.

CAIN, S. A. Life-forms and Phytoclimate. The Botanical Review, v.16, n.1, p.1-32, 1950.

CARvalho, M. C. A. M. Paracatu e o Morro do Ouro. Rio Paracatu Mineração, 1992. 91p.

CORDEIRO, L. Fixação de nitrogênio em leguminosas ocorrentes no Cerrado. In: KLEIN, A. L. (Org.). Eugen warming e o cerrado brasileiro: um século depois. São Paulo: UNESP, 2002. p131-145.

CORREA, R, S.; MELO FILHO, B. Ecologia e recuperação de degradadas no cerrado. Brasília: Paralelo 15, 1998. 178p.

COSTA, A. A.; ARAuJO, G. M. Comparação da vegetação arbórea de cerradão e de cerrado na Reserva do Panga, Uberlândia, Minas Gerais. Acta Botanica Brasílica, v.15, n.1, p.6372, 2001.

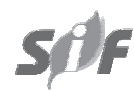

COUTINHO, L. M. O conceito de cerrado. Revista Brasileira de Botânica, v.1, n.1, p.17-23, 1978.

CRONQUIST, A. An integrated system of classification of flowering plants. New York: Columbia University, 1981. 1262p.

FELFILI, J. M. et al. Análise comparativa da florística e fitossociologia da vegetação arbórea do cerrado sensu stricto na Chapada Pratinha, DF-Brasil. Acta Botanica Brasílica, v.6, n.2, p.27-46, 1993.

FERRI, M. G. Ecologia dos cerrados. In: SIMPÓSIO SOBRE O CERRADO: Bases para a Utilização Agropecuária, 4., 1976, Brasília. Anais... Belo Horizonte: Itatiaia, 1977. p.15-36.

MANTOVANI, W.; MARTINS, F. R. Florística do Cerrado na Reserva Biológica de Moji Guaçu, SP. Acta Botanica Brasílica, v.7, n.1, p.33-60, 1993.

MEIRA NETO, J. A. A. A política de conservação da diversidade vegetal nos Cerrados de Minas Gerais. In: CONGRESSO NACIONAL DE BOTÂNICA, 54., 2003, Belém. Anais... Belém: Sociedade de Botânica do Brasil, 2003. p.228-230.

MEIRELLES, S. T.; PIVELLO, V. R.; JOLY, C. A. The vegetation of granite rock outcrops in Rio de Janeiro, Brazil, and the need for its protection. Environmental Conservation, v.26, n.1, p.10-20, 1999.

MUELLER-DOMBOIS, D.; ELLENBERG, H. Aims and methods of vegetation ecology. New York: John Wiley \& Sons, 1974. 547p.

MUNHOZ, C. B. R.; PROENÇA, C. E. B. Composição florística do município de Alto Paraíso na Chapada dos Veadeiros. Boletim do Herbário Ezechias Paulo Heringer, v.3, p.102-150, 1998.

OLIVEIRA FILHO, A. T.; MARTINS, F. R. A comparative study of five cerrado areas in Southern Mato Grosso, Brazil. Edinburgh Journal of Botany, v.48, n.3, p.307-332, 1991.

Revista Árvore, Viçosa-MG, v.35, n.4, p.907-918, 2011 
PRIMACK, R.; MASSARDO, F. Restauraciön ecológica. In: PRIMACK, R. et al. (Ed.).

\section{Fundamentos de conservación}

biológica: perspectivas latinoamericanas. México: Fondo de Cultura Econômica, 2001. p.559-579.

RATTER, J. A.; BRIDGEWATER, S.; RIBEIRO, J. F. Analysis of the floristic composition of the brazilian cerrado vegetation III: comparison of the woody vegetation of 376 areas. Edinburgh Journal of Botany, v.60, n.1, p.57-109, 2003.

SHEPHERD, G. J. Fitopac 1. Manual do usuário. Campinas: Universidade Estadual de Campinas, 1994. 96p.

SNEATH, P. H.; SOKAL, R. R. Numerical taxonomy. New York: W. H. Freeman and Company, 1973. 573p.
SOUZA, V. C.; LORENZI, H. Botânica

sistemática: guia ilustrado para identificação das famílias de Angiospermas da flora brasileira, baseado em APG II. Nova Odessa: Plantarum, 2005. 387p.

VELOSO, H. P. Manual técnico da vegetação brasileira. Rio de Janeiro: IBGE, 1992.92p.

WANDERLEY, M. G. L.; SHEPHERD, G. J.; GIULIETTI, A. M. Flora fanerogâmica do Estado de São Paulo (Poaceae). São Paulo: Fapesp/Hucitec, 2001. 291p.

WARMING, E. Lagoa Santa. In: WARMING, E.; FERRI, M. G. Lagoa Santa, a vegetação de cerrados brasileiros. Belo Horizonte: Itatiaia, 1892. p.1-284. 